BENTHAM OPEN
CrossMark
Content list available at: www.benthamopen.com/TOCIEJ/

EDITORIAL

\title{
Analysis and Design of Transmission Lines, Structures and Foundations
}

The design of overhead electrical transmission lines to transport current is a unique activity involving contribution of many disciplines, within Civil Engineering and others. This movement of power also requires conductors, insulators, supporting structures (or pylons), connecting hardware, good foundations, electrical grounding while satisfying many rules, governmental regulations and guidelines aimed at safety and reliability.

The transmission line industry encompasses a wide range of structural systems and configurations, foundations, materials, hardware and construction practices. The industry now employs steel (both tubular as well as lattice), prestressed concrete, wood (round and laminated) and composites as primary materials. Foundations include direct embedment with several backfill options, concrete drilled shafts, isolated footings, plate anchors and helical screw anchors.

This special issue of the Civil Engineering Journal - with the theme Analysis and Design of Transmission Lines, Structures and Foundations - is intended to present several articles highlighting some of the current research activities taking place in the industry. The issue is organized in 5 papers.

The article titled, End Restraints in Steel Angles in Lattice Towers presents a discussion of the influence of number of bolts on the actual end restraint in a steel angle beam-column in a lattice tower and thereby the buckling capacity. An attempt has been made to quantify the nature of restraint by correlation with full-scale tests.

The article, Design of Direct Embedment Foundations for Poles under Moment Loads in Granular Soils discusses the adaptation of rigid pile theories to direct the embedment of poles subject to bending moment in sandy soils.

The article titled, A Comparative Study of Distribution Structure Cross Arms presents a comparison of the structural response of wood and composite cross arms used in distribution line structures.

The article, Doing More with Less - Application to Transmission Structures details design choices that affect the economy and performance of a transmission structure.

The article titled, Emergency Restoration of High Voltage Transmission Lines discusses emergency restoration plans for transmission lines damaged in hurricanes and how line restoration aspects tie with the economics of line planning and operation.

Although some of the focus in this issue is on U.S. design procedures and standards, the underlying theories and principles are universal and are applicable everywhere.

Sriram Kalaga

Guest Editor

Ulteig Engineers, Inc.

4285 North Lexington Avenue,

St. Paul, Minnesota, USA

E-mail: drkalaga@hotmail.com

1874-1495/17 2017 Bentham Open

This is an open access article distributed under the terms of the Creative Commons Attribution 4.0 International Public License (CC-BY 4.0), a copy of which is available at: https://creativecommons.org/licenses/by/4.0/legalcode. This license permits unrestricted use, distribution, and reproduction in any medium, provided the original author and source are credited. 